\title{
A Novel Fuzzy Sliding-Mode Control for Discrete-Time Uncertain System
}

\author{
T. H. Yan, ${ }^{1}$ B. Wu, ${ }^{1}$ B. He, ${ }^{2}$ W. H. Li, ${ }^{3}$ and R. B. Wang ${ }^{1}$ \\ ${ }^{1}$ School of Mechanical \& Electrical Engineering, China Jiliang University, Hangzhou 310018, China \\ ${ }^{2}$ School of Information Science and Engineering College, Ocean University of China, Qingdao 266100, China \\ ${ }^{3}$ School of Mechanical, Materials and Mechatronic Engineering, University of Wollongong, Wollongong, NSW, Australia
}

Correspondence should be addressed to T. H. Yan; thyan@163.com

Received 19 April 2016; Revised 20 July 2016; Accepted 10 August 2016

Academic Editor: Yan-Jun Liu

Copyright (C) 2016 T. H. Yan et al. This is an open access article distributed under the Creative Commons Attribution License, which permits unrestricted use, distribution, and reproduction in any medium, provided the original work is properly cited.

\begin{abstract}
This paper considers the sliding-mode control problem for discrete-time uncertain systems. It begins by presenting a discrete variable speed reaching law and a discrete-time sliding-mode controller (DSMC) designed using the proposed reaching law, followed by an analysis of their stability and dynamic performance. A sliding-mode controller with simple fuzzy logic is then proposed to further strengthen the dynamic performance of the proposed sliding-mode controller. Finally, the presented DSMC and the DSMC with fuzzy control for adjusting the parameters in this paper are compared with one of the previous proposed classic DSMC systems. The results of this simulation show that the DSMC presented here can suppress chatter and ensure good dynamic performances when fuzzy logic is used to tune the parameters.
\end{abstract}

\section{Introduction}

A sliding-mode control (SMC) system has proved to be an effective control strategy for incompletely modeled or uncertain systems, so much so that many relevant results can be found in various publications, for example, [1-5]. SMC is a popular robust strategy which can offer good robustness against the parameter uncertainties and external disturbance by limiting the effect in a bounded area. The main advantage of SMC is that it can guarantee the stability of the system by switching the control law. Movement in general SMC systems can be divided into a reaching phase and a sliding mode [6] because the basic idea of SMC is to drive system states onto a predefined switching surface and move on it to the point of origin after the system state reaches the switching surface. The need to research SMC in discrete time (DSMC) is due to the widespread use of computers for the control problem. In recent years, DSMC has received a great deal of research interests. A new method of DSMC is proposed in [7]. The algorithm comprises not only functions in the sliding variable but also functions in other variables. It provided a general method to design reaching law. The ideal reaching law is proposed in [8] which used LMI to list sufficient conditions of switching surface existence in Delta operator system, and the result was compared with the index reaching law. Fast convergence and the attenuation of disturbance are studied in [9-11]. In [9], a new controller is present which is able to handle the effect of interconnection for large-scale systems and unmatched uncertainty. It also shows a fast convergence to the desired value. In $[10,11]$, quasi-sliding-mode control was proposed to the system which has eternal disturbance. Fast convergence and small chatting are ensured by using these two algorithms. The applications of DSMC in practical systems are also studied in $[12,13]$ which study the SMC on servo system with external disturbance.

However, its major drawback in practical applications is that the system trajectories of DSMC systems cannot reach their origin. They only tend to reach a chattering stage surrounding the origin [14-16]. Numerous methods have been developed to eliminate this phenomenon in DSMC [1719]; for instance, in [18], robustness is ensured and chattering is eliminated by using an optimal integral sliding surface. An output-feedback quasi-sliding-mode control scheme is proposed in [19] which eliminates the chattering phenomenon 
and also ensures the uncertainties and disturbances are robust. Bartoszewicz designed a quasi-sliding-mode controller for a discrete-time system in [20] that can reduce chattering caused by high frequency. Qu et al. proposed a DSMC with a disturbance compensator in [10] that obviously reduced chattering. A lot of effort has been made to overcome the chattering problem, such as a state observer, adaptive techniques, and an intelligent control method [21-25]. Some other methods also can be applied into DSMC to overcome chattering, like the neural network in [26] which designed the adaptive adjusting parameters in scalar form to reduce the online computation burden and can adjust the sliding surface dynamically and the genetic algorithm in [27] which can optimize the parameters in sliding-mode controller.

Fuzzy control (FC) has been widely used in many practical systems [28-33]. It is a technique that requires expert knowledge to design a controller which is a model-free design method that is insensitive to variations in parameters and external disturbances. In [29], an adaptive fuzzy slidingmode control is used for nonlinear systems to estimate the unknown gain of the switching control. A fuzzy basis function network is used to approximate the unknown dynamics of a robot with two arms [30] and a fuzzy adaptive state observer is designed to estimate the unmeasured state in [32]. Fuzzy control has been widely used to adaptive parameters and optimal control [34-41]. An adaptive fuzzy decentralized output-feedback controller was designed for a class of switched nonlinear large-scale systems which contain the unknown nonlinearities and dead zone in [34]. Chen et al. [35] proposed an adaptive tracking control for a class of nonlinear stochastic systems with unknown functions. The fuzzy-neural networks were used to approximate unknown functions. In [36], Chen et al. considered the problem of observer-based adaptive fuzzy control for a class of nonlinear time-delay systems in nonstrict-feedback form. The fuzzy logic systems were used to approximate the unknown nonlinear functions. In [37], a hybrid task-space trajectory and force tracking based on fuzzy system and adaptive mechanism were proposed to compensate for the external perturbation, kinematics, and dynamic uncertainties. Liu et al. [38] proposed an adaptive fuzzy optimal control for a class of unknown nonlinear discrete-time systems which contained unknown functions and nonsymmetric dead zone. The fuzzy logic systems were employed to approximate the functions in the systems. In [39], an adaptive fuzzy inverse compensation control method was proposed for uncertain nonlinear system, and an adaptive fuzzy controller was developed to establish the close-loop system stability. For the Henon Mapping chaotic system, Gao and Liu [40] proposed a direct heuristic dynamic programming to handle the optimal tracking control, and the fuzzy logic system is applied to measure the long-term utility function. In [41], an adaptive fuzzy controller was proposed for uncertain nonlinear systems with backlash. The fuzzy logic systems were used to approximate the unknown functions, unknown backlash, and backlash inversion. One feature of fuzzy control is that "if-then" rules are based on expert knowledge $[42,43]$. Fuzzy sliding-mode control (FSMC) combines two theories of FC and SMC, which means the fuzzy control method can optimize SMC dynamically in more detail [44-46]. For example, when a system trajectory is leaving the switching surface, it can provide a large control force to drive the trajectory back to the switching surface according to fuzzy rules.

In order to reduce the chattering and accelerating convergent speed in discrete-time uncertain systems, a new reaching law is proposed for discrete-time systems with external disturbances. It begins by introducing a discretetime system with external disturbances, the proposed SMC, and then a FMSC is proposed to improve the reaching phase. This method guarantees the robust behavior of the system, whereas FSMC improves system performance based on a performance analysis. Simulated examples are given to verify the proposed method, followed by the conclusions.

\section{System Description}

The general description of a single-input uncertain system is as follows:

$$
\dot{x}=A x+B u+D f
$$

where $x=\left[\begin{array}{llll}x_{1} & x_{2} & \cdots & x_{n}\end{array}\right]^{T} \in R^{n}$ is the state, $u \in R^{1}$ is the control input, and $f \in R^{n}$ denotes the external disturbance. $A, B$, and $D$ are known real constant matrices of appropriate dimensions. Without losing any generality, it is assumed that the pair $(A, B)$ is completely controllable, and the disturbance $f$ is bounded; that is,

$$
|f(t)| \leq M
$$

where $M$ is a positive and known constant. It should be noted that the uncertainty means the system contains external disturbance in our system.

In order to alleviate chattering, the sample hold effects should be taken into account, so by applying zero-order-hold (ZOH) sampling [47], the discrete-time description of system (1) can be written as

$$
x(k+1)=G x(k)+H u(k)+d(k),
$$

where $x(k)=x(k T), G=e^{A T}, H=\int_{0}^{T} e^{A \tau} d \tau B, u(k)=u(k T)$, $d(k)=\int_{0}^{T} e^{A \tau} D f((k+1) T-\tau) d \tau$, and $T$ is the sampling period.

The goal here is to design a suitable FSMC controller for system (3). The switching function $s(k)$ is defined as

$$
s(k)=C^{T} x(k)=\sum_{i=1}^{n} c_{i} x_{i}(k),
$$

where $C=\left[\begin{array}{llll}c_{1} & c_{2} & \cdots & c_{n}\end{array}\right]^{T}$ is designed to drive the system to the origin when travelling along the switching surface:

$$
S=\left\{x(k) \mid C^{T} x(k)=0\right\} .
$$

The control object is to drive the system to the switching surface $S$ defined in (5) and travel to the origin point along the switching surface $S$. 


\section{Fuzzy Sliding-Mode Control Design}

The variable speed reaching law is a kind of common reaching law [48] that can effectively overcome the chattering problem; its continuous form is

$$
\dot{s}=-\varepsilon\|x\|_{1} \operatorname{sgn}(s)
$$

and its discrete form is

$$
s(k+1)-s(k)=-\varepsilon T\|x(k)\|_{1} \operatorname{sgn}(s(k)),
$$

where $\varepsilon>0,\|x(k)\|_{1}$ is the state norm, and $T$ is the sampling period.

From this reaching law, we get the following controller for system (3):

$$
\begin{aligned}
& u(k)=\left(C^{T} H\right)^{-1}\left(s(k)-\varepsilon T\|x(k)\|_{1} \operatorname{sgn}(s(k))\right. \\
& \left.-C^{T} G x(k)-C^{T} d(k)\right) .
\end{aligned}
$$

The variable speed reaching law (7) can overcome the chattering problem, but there are two shortages: one is that the chattering will be serious at the beginning of the reaching phase, and the other is that the reaching speed is too slow near the switching surface. These two shortages will seriously affect the system performance.

3.1. The New Reaching Law Design. The discrete form of the improved variable speed reaching law is

$$
s(k+1)-s(k)=-\alpha T \log _{2}\left(|s(k)|^{\beta}+1\right) \operatorname{sgn}(s(k)),
$$

where $\alpha, \beta>0$.

From this reaching law, we get the following controller for system (3):

$$
\begin{aligned}
& u(k)=\left(C^{T} H\right)^{-1}(s(k) \\
& -\alpha T \log _{2}\left(|s(k)|^{\beta}+1\right) \operatorname{sgn}(s(k))-C^{T} G x(k) \\
& \left.-C^{T} d(k)\right) .
\end{aligned}
$$

To ensure the system can meet its performance requirements, we analyzed the system as follows.

3.2. Stability Analysis. To design a sliding-mode controller for discrete-time uncertain system, the following two conditions should be met to guarantee the system trajectory reaching the switching surface and converge to zero in a limited time [49]:

$$
\begin{aligned}
& (s(k+1)-s(k)) s(k)<0 \\
& (s(k+1)+s(k)) s(k)>0 .
\end{aligned}
$$

Substituting the reaching law (9) to condition (11) yields

$$
\begin{aligned}
& (s(k+1)-s(k)) s(k) \\
& \quad=-\alpha T \log _{2}\left(|s(k)|^{\beta}+1\right) \operatorname{sgn}(s(k)) s(k) \\
& \quad=-\alpha T|s(k)| \log _{2}\left(|s(k)|^{\beta}+1\right)<0 \\
& (s(k+1)+s(k)) s(k) \\
& \quad=\left(2 s(k)-\alpha T \log _{2}\left(|s(k)|^{\beta}+1\right) \operatorname{sgn}(s(k))\right) s(k) \\
& \quad=2|s(k)|^{2}-\alpha T|s(k)| \log _{2}\left(|s(k)|^{\beta}+1\right) .
\end{aligned}
$$

When $s(k)$ is very small, by using the equivalent infinitesimal, we can get

$$
\begin{aligned}
& (s(k+1)+s(k)) s(k) \approx 2|s(k)|^{2}-\alpha \beta T|s(k)|^{2} \\
& \quad=(2-\alpha \beta T)|s(k)|^{2} .
\end{aligned}
$$

To guarantee $(s(k+1)+s(k)) s(k)>0, \alpha \beta T$ must be less than 2. When $s(k)$ is big, we get the following formula:

$$
\begin{aligned}
& (s(k+1)+s(k)) s(k)>2|s(k)|^{2}-\alpha T|s(k)|^{2} \\
& \quad=(2-\alpha T)|s(k)|^{2} .
\end{aligned}
$$

So if $\alpha T<2$, then $(s(k+1)+s(k)) s(k)>0$ is guaranteed. So when $\alpha \beta T<2$ and $\alpha T<2$, the system trajectory can reach the switching surface and converge to zero in a limited time.

Specifically, when $s(k)=0$, we can get $s(k+1)=0$ from (9). So in the next time, $s(k)$ will be zero all the time if there is no disturbance. Therefore, the proposed reaching law (9) can meet conditions (11), which means that the switching surface is existent and the system trajectory will reach the surface in a limited time.

According to the abovementioned analysis, the system trajectory will enter a region near the switching surface and will not go away. So we can conclude that system (3) with controller (10) is stable and it will reach the surface in a limited time.

3.3. Dynamic Performance Analysis. From reaching law (9), we can obtain the following two formulas:

$$
\begin{aligned}
& s(k+1)=-\alpha T \log _{2}\left(|s(k)|^{\beta}+1\right), \quad \text { when } s(k)=0^{+} \\
& s(k+1)=\alpha T \log _{2}\left(|s(k)|^{\beta}+1\right), \quad \text { when } s(k)=0^{-} .
\end{aligned}
$$

We define the switching region as

$$
S_{\Delta}=\left\{x(k) \mid-\Delta<C^{T} x(k)<\Delta\right\},
$$

where $\Delta=\alpha T \log _{2}\left(|s(k)|^{\beta}+1\right)$. The width of the switching region is

$$
2 \Delta=2 \alpha T \log _{2}\left(|s(k)|^{\beta}+1\right) .
$$

Meanwhile, the width in reaching law (7) is $2 \varepsilon T\|x(k)\|_{1}$. Based on the functions $f_{1}(x)=k \log _{2}(x+1)$ and $f_{2}(x)=k x$, 


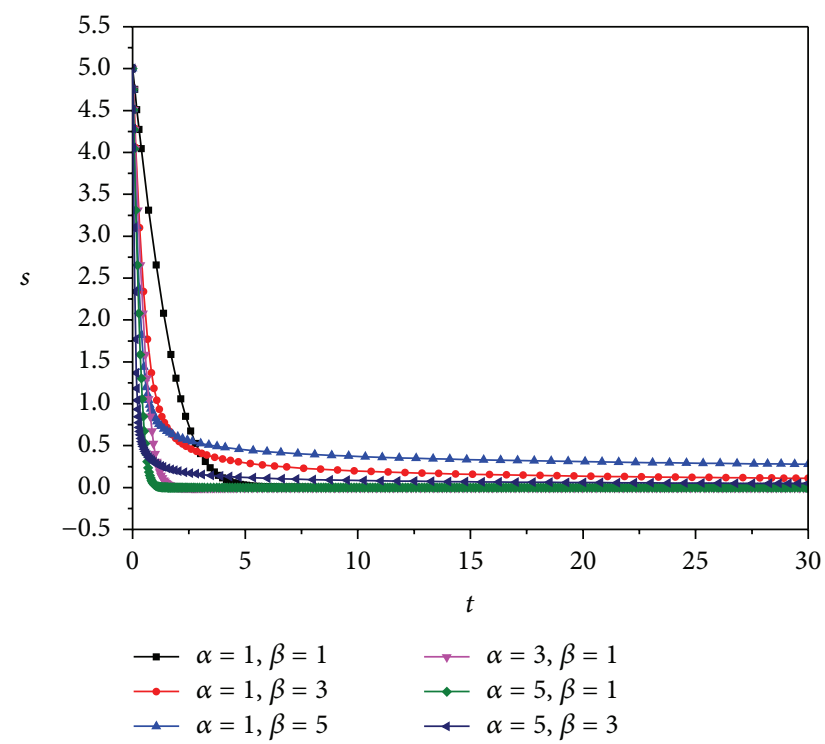

FIgURE 1: The effect of $\alpha$ and $\beta$ on the reaching rate.

by comparing the width between reaching laws (9) and (7), we find that the width we proposed is smaller than (7), which means the system trajectory will be in a smaller region when it crosses the switching surface. So the system with controller (10) has a smaller chatting than controller (8).

To analyze the parameters of the proposed reaching law, the derived reaching rate is given here. The derivative of a continuous system is defined as follows [50]:

$$
\dot{s}(t)=\lim _{\Delta t \rightarrow 0} \frac{s(t+\Delta t)-s(t)}{\Delta t} .
$$

Assuming

$$
\Delta s(k)=s(k+1)-s(k)
$$

if the sampling period $T$ is small enough, the following equation can be obtained:

$$
\begin{aligned}
\dot{s}(t) & =\frac{\Delta s}{T}=\frac{s(k+1)-s(k)}{T} \\
& =-\alpha \log _{2}\left(|s(k)|^{\beta}+1\right) \operatorname{sgn}(s(k)) .
\end{aligned}
$$

For the first-order differential equation $\dot{s}=f(s)$, we give a numerical solution for (20) with different values of $\alpha$ and $\beta$. Here, we assumed $s(0)=5$. Figure 1 shows how $\alpha$ and $\beta$ affect the reaching rate.

Figure 1 indicates that when $\alpha$ and $\beta$ are increasing, the reaching rate is faster, but when $\beta$ is larger, the reaching rate near the sliding surface is smaller. The results of simulating sliding dynamics indicate that when $\alpha$ and $\beta$ are too big, the chattering problem will be terrible, so based on the experience of $\alpha$ and $\beta$, the reaching law (9) we presented here has further improvements in DSMC.

3.4. Further Improvement. Based on shortages of the reaching law (9), we used fuzzy control (FC) to adjust the parameters $\alpha$ and $\beta$ by referring to Figure 1 .

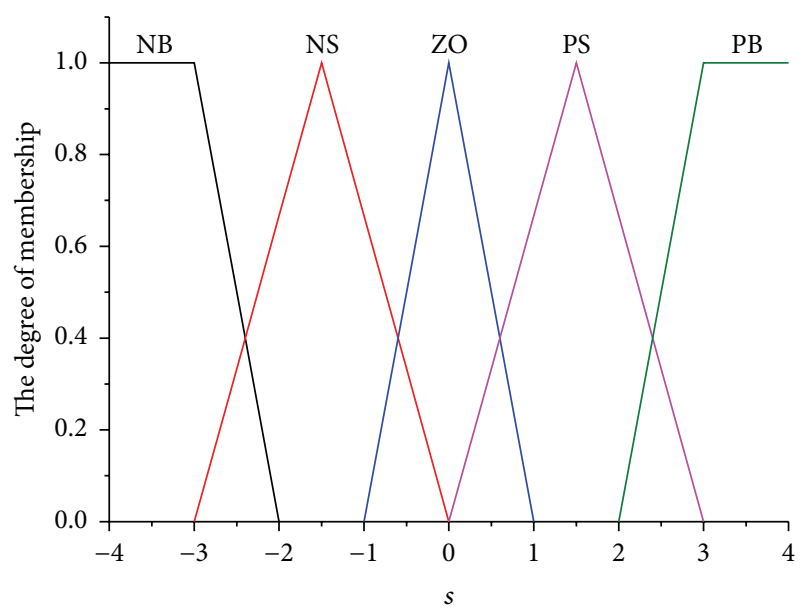

FIGURE 2: Membership function of input variables.

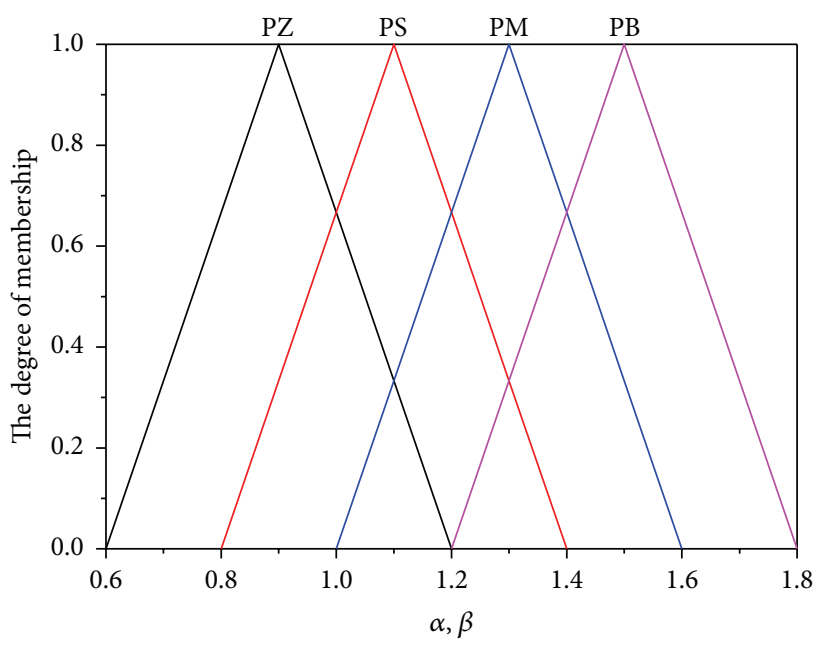

FIGURE 3: Membership function of output variables.

FC has replaced conventional technologies in many fields. One major feature of FC is its ability to express ambiguous thinking, so when the mathematical model of a system exists accurately or exists but with uncertainties, FC can deal with the unknown process efficiently, although it will sometimes complicate the analysis due to the huge number of fuzzy rules for high-order systems. To eliminate the chattering problem and accelerate the reaching rate in this study, a fuzzy slidingmode control method is proposed. The membership function of our FSMC method is shown in Figures 2 and 3; it is a oneinput-two-output FSMC, and because there is only one input, the number of fuzzy rules is greatly reduced. Fuzzy control rules are designed to map the input linguistic variables $s$ to the output linguistic variables $\alpha$ and $\beta$ as follows:

$$
\alpha, \beta=\operatorname{FSMC}(s),
$$

where $\operatorname{FSMC}(s)$ means that $\alpha$ and $\beta$ are the function of switching function $s$.

Here, the membership functions of $\alpha$ and $\beta$ are normalized in the interval $[0.6,1.8]$, such that $\alpha, \beta>0$ and satisfy condition (11). 
In our article, the Mamdani fuzzy inference method [51] is used to determine the fuzzy rule such that

$$
\text { if } s \text { is } P_{i} \text {, then } \alpha \text { is } M_{i} \text { and } \beta \text { is } N_{i} \text {. }
$$

The FC we proposed has one input $(s)$ and two outputs $(\alpha, \beta)$. Linguistic variables which imply inputs are classified as NB, NS, ZO, PS, and PB, and outputs are classified as PZ, PS, $\mathrm{PM}$, and $\mathrm{PB}$. Inputs are normalized in an interval of $[-4,4]$, and outputs are normalized in $[0.6,1.8]$, as shown in Figures 2 and 3 . It is possible to assign a set of decision rules as shown in the following based on Figure 1. These rules contain the relationships between input and output that define the control strategy. Each control input has five fuzzy sets so there are only 5 fuzzy rules; this overcomes the problem of complex fuzzy rules.

The fuzzy rule set designed for FSMC is

if $s$ is $\mathrm{NB}$, then $\alpha$ is $\mathrm{PS}$ and $\beta$ is $\mathrm{PB}$

if $s$ is NS, then $\alpha$ is PS and $\beta$ is PM

if $s$ is $\mathrm{ZO}$, then $\alpha$ is $\mathrm{PZ}$ and $\beta$ is $\mathrm{PZ}$

if $s$ is PS, then $\alpha$ is PS and $\beta$ is PM

if $s$ is $\mathrm{PB}$, then $\alpha$ is $\mathrm{PS}$ and $\beta$ is $\mathrm{PB}$.

Finally, defuzzification should be designed to determine the numerical value of $\alpha$ and $\beta$ based on the fuzzy rule set. Here, the centre average method is used for defuzzification as follows:

$$
\alpha, \beta=\frac{\int_{V} v \mu_{v}(v) d v}{\int_{V} \mu_{v}(v) d v},
$$

where $V$ is the domain of linguistic variables $\alpha$ and $\beta . v$ is the point at which the membership function of $M_{i}\left(N_{i}\right)$ of $\alpha(\beta)$ achieves its maximum and $\mu_{v}(v)$ is the degree of membership of $s$ to $P_{i}$.

From what has been discussed above, a fuzzy slidingmode controller can be obtained; however, the experience of experts should be referred to if the membership function and fuzzy rule set need to be adjusted for different problems. Here, experience was gained from Figure 1, which shows how $\alpha$ and $\beta$ affect system performance.

\section{Numerical Simulation}

Consider a second-order system with time-varying uncertain [10] as follows:

$$
\dot{x}=\left[\begin{array}{cc}
0 & 1 \\
5 & -2
\end{array}\right] x+\left[\begin{array}{l}
0 \\
1
\end{array}\right] u+\left[\begin{array}{c}
0 \\
1+2.2 \cos (0.5 \pi t)
\end{array}\right] .
$$

When the sampling period $T=0.1$, the discrete-time description of system (25) can be obtained as

$$
x(k+1)=G x(k)+H u(k)+d(k),
$$

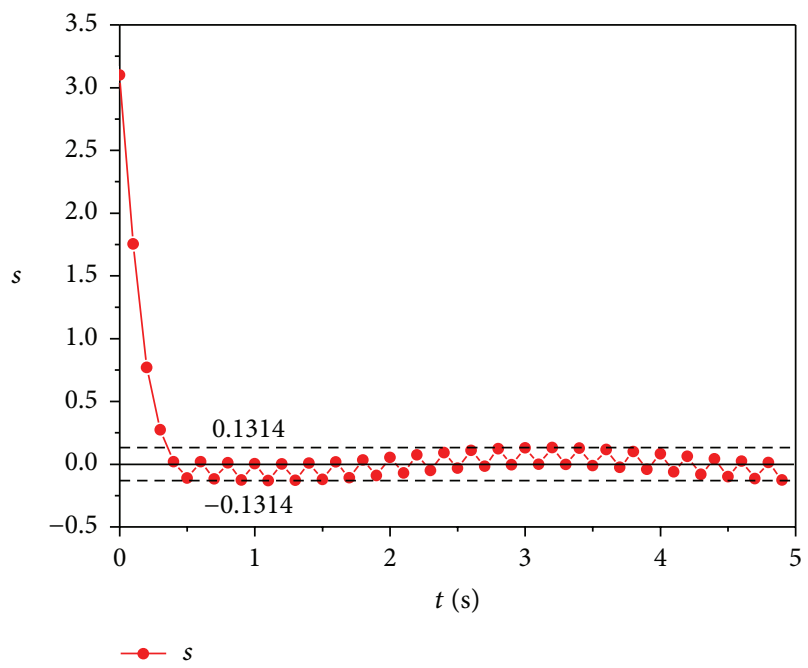

FIGURE 4: Switching function with controller (28).

where

$$
\begin{aligned}
G & =\left[\begin{array}{ll}
1.02351 & 0.09139 \\
0.45696 & 0.84073
\end{array}\right], \\
H & =\left[\begin{array}{l}
0.00470 \\
0.09139
\end{array}\right], \\
d(k) & =\left[\begin{array}{ll}
0.10080 & 0.00470 \\
0.02351 & 0.09139
\end{array}\right]\left[\begin{array}{c}
0 \\
1+2.2 \cos (0.5 \pi k T)
\end{array}\right] .
\end{aligned}
$$

Here, the initial state was assumed to be $x(0)=\left[\begin{array}{ll}2.1 & 1\end{array}\right]^{T}$ and $C=\left[\begin{array}{ll}1 & 1\end{array}\right]^{T}$. It should be pointed out that a long sampling period was chosen to exhibit the system dynamics.

In the following, we used different controllers to compare the controlling performance of system (26).

Case 1. Consider system (26), when controller (14) in [10] is implemented with the expression that is

$$
\begin{aligned}
& u(k)=\left(C^{T} H\right)^{-1}\left\{C^{T} G-(1-q) s(k)\right. \\
& +\varepsilon T \operatorname{sgn}(s(k))+\sum_{i=1}^{k}[s(i)-(1-q T) s(i-1) \\
& \quad+\varepsilon T \operatorname{sgn}(s(i-1))]\}
\end{aligned}
$$

where $q=5$ and $\varepsilon=1$. System performances are shown in Figures 4-6 and indicate that when the system trajectory is close to the sliding surface, chattering is small, but this chattering cannot reach the origin; it can only surround the origin.

Case 2. When controller (8) with parameters $\alpha=1, \beta=1$ is implemented for system (26), then system performances 


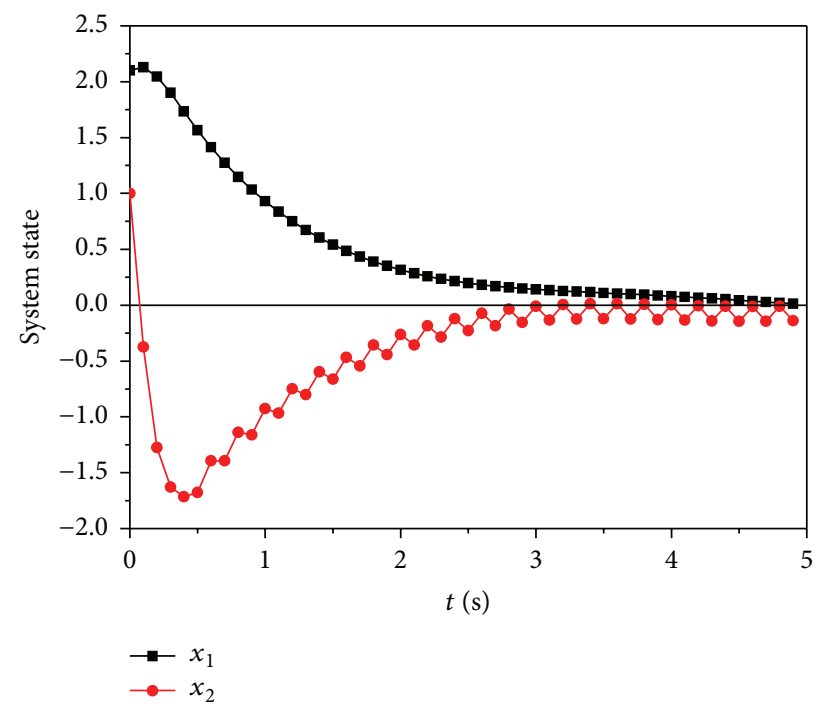

Figure 5: System states with controller (28).

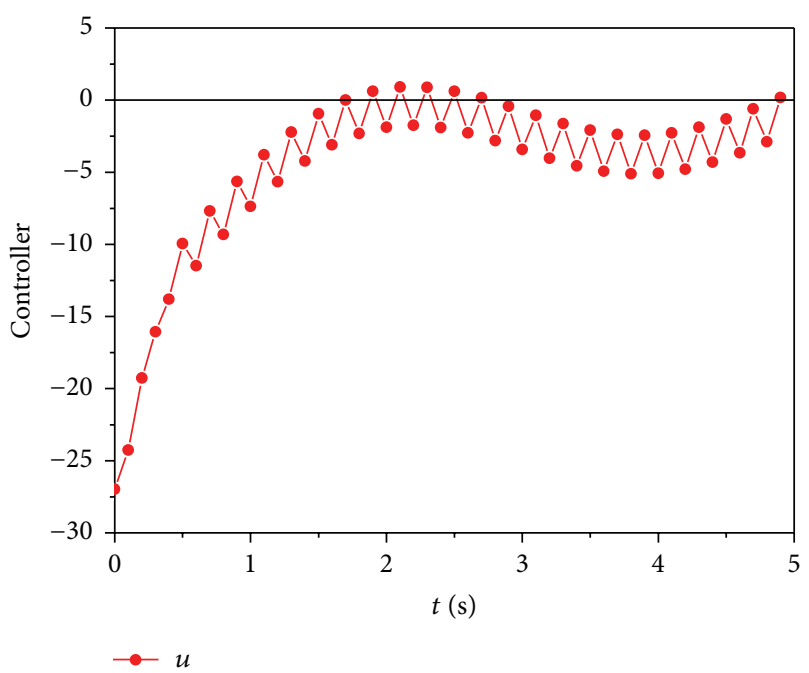

Figure 6: Controller (28).

are shown in Figures 7-9, respectively. Unlike controller (28), the reaching rate accelerates at the beginning and chattering decreases, but the reaching rate at the beginning has evidently not improved; this can also be gleaned from Figure 1 where $\alpha=\beta=1$.

Case 3. When controller (8) is implemented for system (26), then by using FLC (21) to adjust parameters $\alpha$ and $\beta$, the switching function, system states, and controller are shown in Figures 10-12. Figure 10 shows that the dynamics of FSMC have improved the reaching rate in all regions and overcome the chattering problem.

From what has been discussed above, the SMC and FSMC methods we proposed for discrete-time system with uncertainty are very capable, and the proposed reaching law performed better than (28). By improving the reaching law

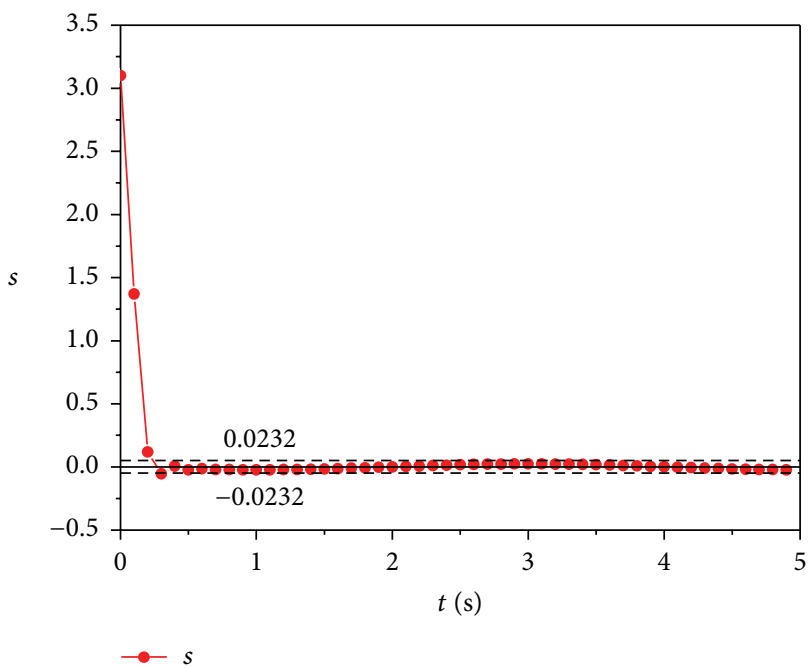

FIGURE 7: Switching function with controller (10).

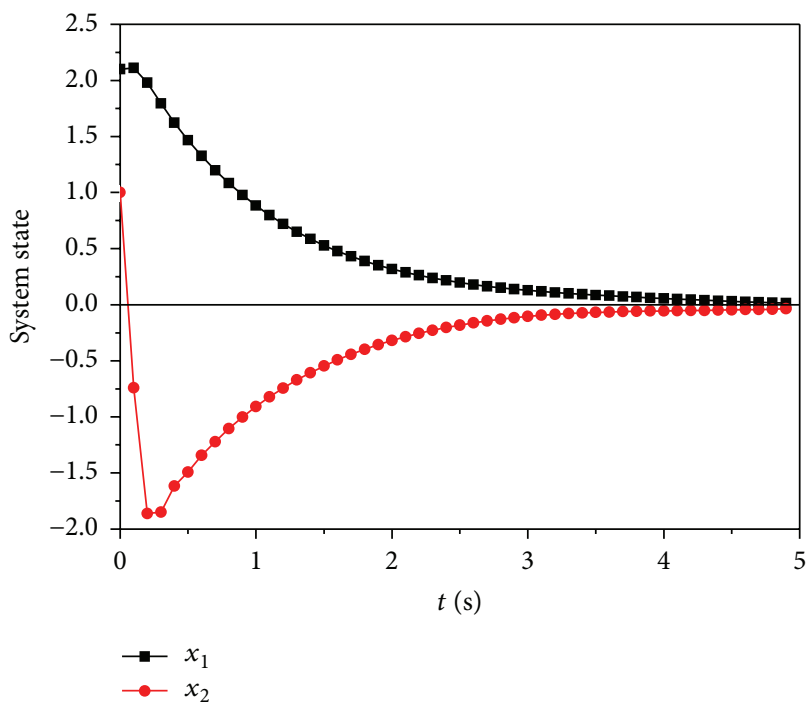

Figure 8: System states with controller (10).

with fuzzy logic, the system presents much better dynamic performances at every stage.

\section{Conclusion}

This paper has presented a new discrete reaching law, and a discrete sliding-mode controller with fuzzy logical control has been designed by using the proposed reaching law and fuzzy set. A comparison of three cases, that is, (1) the previous DSMC presented by [10], (2) the DSMC presented in the paper, and (3) a DSMC presented with fuzzy control, has been carried out. The experimental results show the obvious effectiveness of the proposed SMC, especially with fuzzy control. In the method presented, the chattering phenomenon that frequently appears in a conventional SMC was overcome, and the reaching rate has also been accelerated. 


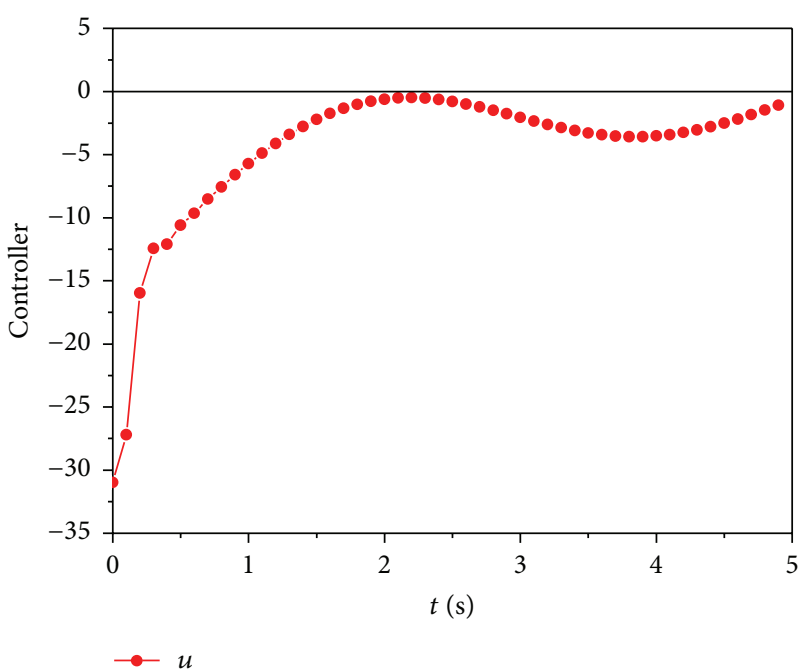

Figure 9: Controller (10).

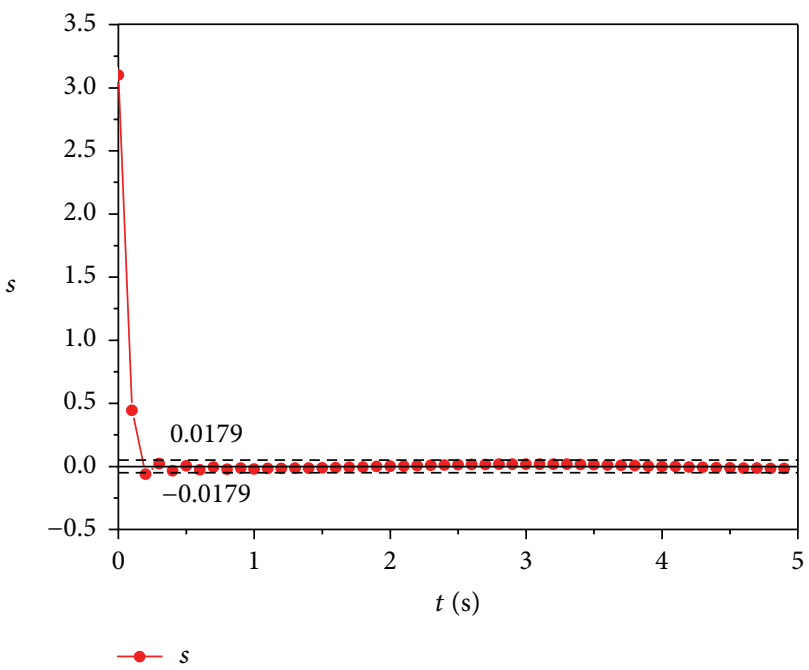

FIGURE 10: Switching function with controller FSMC.

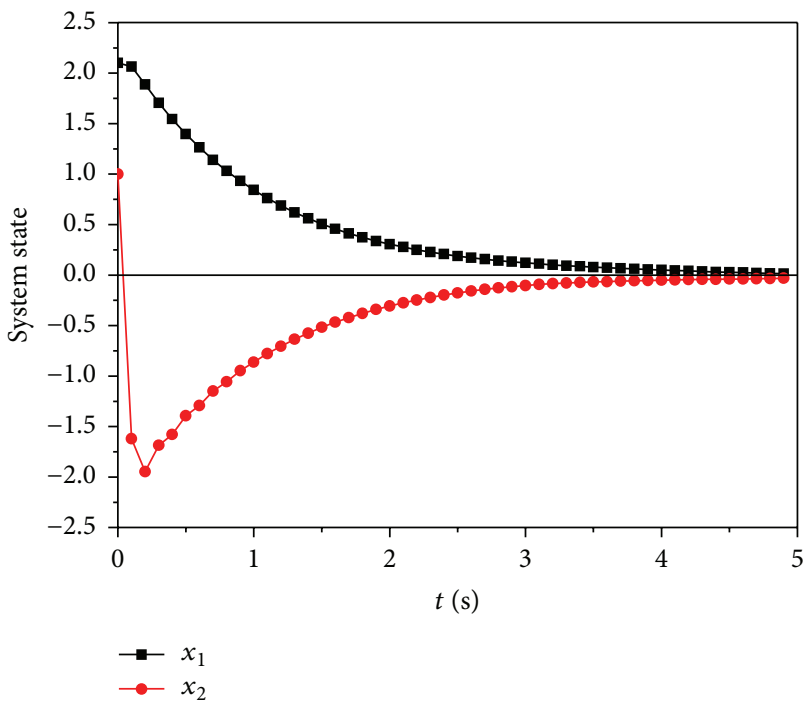

FIGURE 11: System states with controller FSMC.

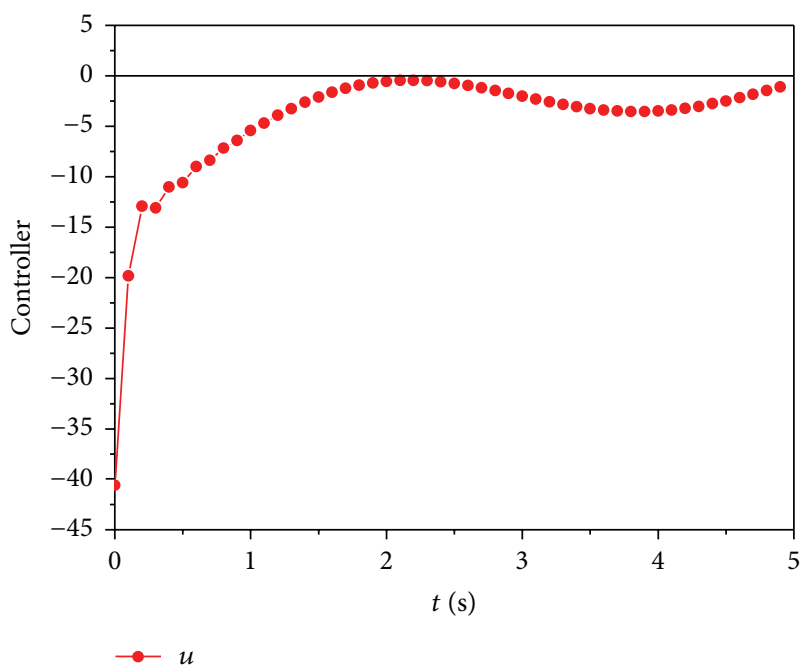

Figure 12: Controller FSMC.

\section{Competing Interests}

The authors declare that they have no competing interests.

\section{Acknowledgments}

This work is partially supported by the Natural Science Foundation of China and Key Research and Development Program of China (51379198, 2016YFC0301404, 41176076, and 31202036).

\section{References}

[1] F. Valenciaga and R. D. Fernandez, "Multiple-input-multipleoutput high-order sliding mode control for a permanent magnet synchronous generator wind-based system with grid support capabilities," IET Renewable Power Generation, vol. 9, no. 8, pp. 925-934, 2015.

[2] W.-J. Chang, P.-H. Chen, and C.-C. Ku, "Mixed sliding mode fuzzy control for discrete-time non-linear stochastic systems subject to variance and passivity constraints," IET Control Theory \& Applications, vol. 9, no. 16, pp. 2369-2376, 2015.

[3] S. Mobayen, "An adaptive chattering-free PID sliding mode control based on dynamic sliding manifolds for a class of uncertain nonlinear systems," Nonlinear Dynamics, vol. 82, no. 1-2, pp. 53-60, 2015.

[4] T. Yoshimura, "Design of an adaptive fuzzy sliding mode control for uncertain discrete-time nonlinear systems based on noisy measurements," International Journal of Systems Science, vol. 47, no. 3, pp. 617-630, 2016.

[5] Y. H. Liu, T. G. Jia, Y. G. Niu, and Y. Y. Zou, "Design of sliding mode control for a class of uncertain switched systems," International Journal of Systems Science, vol. 46, no. 6, pp. 9931002, 2015.

[6] S. Mobayen, "Design of CNF-based nonlinear integral sliding surface for matched uncertain linear systems with multiple state-delays," Nonlinear Dynamics, vol. 77, no. 3, pp. 1047-1054, 2014. 
[7] S. Chakrabarty and B. Bandyopadhyay, "A generalized reaching law for discrete time sliding mode control," Automatica, vol. 52, pp. 83-86, 2015.

[8] J. Sun, "Chattering-free sliding-mode variable structure control of delta operator system," Journal of Computational and Theoretical Nanoscience, vol. 11, no. 10, pp. 2150-2156, 2014.

[9] C. H. Chai and J. H. S. Osman, "Discrete-time integral sliding mode control for large-scale system with unmatched uncertainty," Control Engineering and Applied Informatics, vol. 17, no. 3, pp. 3-11, 2015.

[10] S. C. Qu, X. H. Xia, and J. F. Zhang, "Dynamics of discrete-time sliding-mode-control uncertain systems with a disturbance compensator," IEEE Transactions on Industrial Electronics, vol. 61, no. 7, pp. 3502-3510, 2014.

[11] M. Wu and J. S. Chen, "A discrete-time global quasi-sliding mode control scheme with bounded external disturbance rejection," Asian Journal of Control, vol. 16, no. 6, pp. 1839-1848, 2014.

[12] Č. Milosavljević, B. Peruničić-Draženović, and B. Veselić, "Discrete-time velocity servo system design using sliding mode control approach with disturbance compensation," IEEE Transactions on Industrial Informatics, vol. 9, no. 2, pp. 920-927, 2013.

[13] H.-R. Li, Z.-B. Jiang, and N. Kang, "Sliding mode disturbance observer-based fractional second-order nonsingular terminal sliding mode control for PMSM position regulation system," Mathematical Problems in Engineering, vol. 2015, Article ID 370904, 14 pages, 2015.

[14] W. Gao, Y. Wang, and A. Homaifa, "Discrete-time variable structure control systems," IEEE Transactions on Industrial Electronics, vol. 42, no. 2, pp. 117-122, 1995.

[15] S. J. Wang, L. Hou, L. Dong, and H. J. Xiao, "Adaptive fuzzy sliding mode control of uncertain nonlinear SISO systems," Procedia Engineering, vol. 24, pp. 33-37, 2011.

[16] N. D. That and Q. P. Ha, "Discrete-time sliding mode control with state bounding for linear systems with time-varying delay and unmatched disturbances," IET Control Theory \& Applications, vol. 9, no. 11, pp. 1700-1708, 2015.

[17] S. Govindaswamy, T. Floquet, and S. K. Spurgeon, "Discrete time output feedback sliding mode tracking control for systems with uncertainties," International Journal of Robust and Nonlinear Control, vol. 24, no. 15, pp. 2098-2118, 2014.

[18] N. N. Sun, Y. G. Niu, and B. Chen, "Optimal integral sliding mode control for a class of uncertain discrete-time systems," Optimal Control Applications \& Methods, vol. 35, no. 4, pp. 468478, 2014.

[19] M.-C. Pai, "Discrete-time output feedback quasi-sliding mode control for robust tracking and model following of uncertain systems," Journal of the Franklin Institute, vol. 351, no. 5, pp. 2623-2639, 2014.

[20] A. Bartoszewicz, "Discrete-time quasi-sliding-mode control strategies," IEEE Transactions on Industrial Electronics, vol. 45, no. 4, pp. 633-637, 1998.

[21] M. Mirzaei, F. S. Nia, and H. Mohammadi, "Applying adaptive fuzzy sliding mode control to an underactuated system," in Proceedings of the 2nd International Conference on Control, Instrumentation and Automation (ICCIA '11), pp. 654-659, Shiraz, Iran, December 2011.

[22] C.-M. Lin and C.-F. Hsu, "Adaptive fuzzy sliding-mode control for induction servomotor systems," IEEE Transactions on Energy Conversion, vol. 19, no. 2, pp. 362-368, 2004.

[23] Y. M. Fang, J. T. Fei, and K. Q. Ma, "Model reference adaptive sliding mode control using RBF neural network for active power filter," International Journal of Electrical Power \& Energy Systems, vol. 73, pp. 249-258, 2015.

[24] C.-F. Hsu, B.-K. Lee, and C.-W. Chang, "Design of an intelligent exponential-reaching sliding-mode control via recurrent fuzzy neural network," in Proceedings of the 11th IEEE International Conference on Control and Automation (ICCA '14), pp. 568-573, Taichung, Taiwan, June 2014.

[25] T.-C. Lin and M.-C. Chen, "Adaptive hybrid type-2 intelligent sliding mode control for uncertain nonlinear multivariable dynamical systems," Fuzzy Sets and Systems, vol. 171, no. 1, pp. 44-71, 2011.

[26] G.-X. Wen, C. L. P. Chen, Y.-J. Liu, and Z. Liu, "Neural-networkbased adaptive leader-following consensus control for secondorder non-linear multi-agent systems," IET Control Theory \& Applications, vol. 9, no. 13, pp. 1927-1934, 2015.

[27] B. Feng, J. Yang, J. G. Ren, and D. S. Zhang, "Control parameters optimization for servo feed system using an improvedgenetic algorithm," in Proceedings of the 11th World Congress on Intelligent Control and Automation (WCICA '14), pp. 4865-4870, Shenyang, China, June 2014.

[28] P. Balasubramaniam, P. Muthukumar, and K. Ratnavelu, "Theoretical and practical applications of fuzzy fractional integral sliding mode control for fractional-order dynamical system," Nonlinear Dynamics, vol. 80, no. 1-2, pp. 249-267, 2015.

[29] T. Yoshimura, "Adaptive fuzzy sliding mode control for uncertain multi-input multi-output discrete-time systems using a set of noisy measurements," International Journal of Systems Science, vol. 46, no. 2, pp. 255-270, 2015.

[30] W. D. Zheng, G. Wu, G. Xu, and X. C. Chen, "Adaptive fuzzy sliding-mode control of uncertain nonlinear system," in Proceedings of the International Conference on Management, Education, Information and Control, vol. 125, pp. 707-711, 2015.

[31] Y. M. Li and S. C. Tong, "Hybrid adaptive fuzzy control for uncertain MIMO nonlinear systems with unknown deadzones," Information Sciences, vol. 328, pp. 97-114, 2016.

[32] W. X. Shi, "Observer-based indirect adaptive fuzzy control for SISO nonlinear systems with unknown gain sign," Neurocomputing, vol. 171, pp. 1598-1605, 2016.

[33] S. Wen and Y. Yan, "Robust adaptive fuzzy control for a class of uncertain MIMO nonlinear systems with input saturation," Mathematical Problems in Engineering, vol. 2015, Article ID 561397, 14 pages, 2015.

[34] S. Tong, L. Zhang, and Y. Li, “Observed-based adaptive fuzzy decentralized tracking control for switched uncertain nonlinear large-scale systems with dead zones," IEEE Transactions on Systems, Man, \& Cybernetics: Systems, vol. 46, no. 1, pp. 37-47, 2015.

[35] C. L. P. Chen, Y.-J. Liu, and G.-X. Wen, "Fuzzy neural networkbased adaptive control for a class of uncertain nonlinear stochastic systems," IEEE Transactions on Cybernetics, vol. 44, no. 5, pp. 583-593, 2014.

[36] B. Chen, C. Lin, X. Liu, and K. Liu, "Observer-based adaptive fuzzy control for a class of nonlinear delayed systems," IEEE Transactions on Systems, Man \& Cybernetics: Systems, vol. 46, no. 1, pp. 27-36, 2015.

[37] Z. J. Li, S. T. Xiao, S. Z. S. Ge, and H. Su, "Constrained multilegged robot system modeling and fuzzy control with uncertain kinematics and dynamics incorporating foot force optimization," IEEE Transactions on Systems, Man, \& Cybernetics: Systems, vol. 46, no. 1, pp. 1-15, 2016.

[38] Y. J. Liu, Y. Gao, S. C. Tong, and Y. M. Li, "Fuzzy approximationbased adaptive backstepping optimal control for a class of 
nonlinear discrete-time systems with dead-zone," IEEE Transactions on Fuzzy Systems, vol. 24, no. 1, pp. 16-28, 2016.

[39] G. Y. Lai, Z. Liu, Y. Zhang, C. L. P. Chen, S. Xie, and Y.-J. Liu, "Fuzzy adaptive inverse compensation method to tracking control of uncertain nonlinear systems with generalized actuator dead zone," IEEE Transactions on Fuzzy Systems, 2016.

[40] Y. Gao and Y.-J. Liu, "Adaptive fuzzy optimal control using direct heuristic dynamic programming for chaotic discretetime system," Journal of Vibration and Control, vol. 22, no. 2, pp. 595-603, 2016.

[41] Y.-J. Liu and S. Tong, "Adaptive fuzzy control for a class of nonlinear discrete-time systems with backlash," IEEE Transactions on Fuzzy Systems, vol. 22, no. 5, pp. 1359-1365, 2014.

[42] T.-S. Li, S.-C. Tong, and G. Feng, "A novel robust adaptivefuzzy-tracking control for a class of nonlinearmulti-input/ multi-output systems," IEEE Transactions on Fuzzy Systems, vol. 18, no. 1, pp. 150-160, 2009.

[43] W.-J. Chang and F.-L. Hsu, "Sliding mode fuzzy control for Takagi-Sugeno fuzzy systems with bilinear consequent part subject to multiple constraints," Information Sciences, vol. 327, pp. 258-271, 2016.

[44] A. F. Amer, E. A. Sallam, and W. M. Elawady, "Adaptive fuzzy sliding mode control using supervisory fuzzy control for 3 DOF planar robot manipulators," Applied Soft Computing, vol. 11, no. 8, pp. 4943-4953, 2011.

[45] Q. Chen, Y.-R. Nan, H.-H. Zheng, and X.-M. Ren, “Full-order sliding mode control of uncertain chaos in a permanent magnet synchronous motor based on a fuzzy extended state observer," Chinese Physics B, vol. 24, no. 11, Article ID 110504, pp. 1-6, 2015.

[46] S. Masumpoor, H. Yaghobi, and M. A. Khanesar, "Adaptive sliding-mode type-2 neuro-fuzzy control of an induction motor," Expert Systems with Applications, vol. 42, no. 19, pp. 6635-6647, 2015.

[47] B. Wang, X. H. Yu, and G. R. Chen, " $\mathrm{ZOH}$ discretization effect on single-input sliding mode control systems with matched uncertainties," Automatica, vol. 45, no. 1, pp. 118-125, 2009.

[48] L. Z. Song, H. Wen, and Q. H. Yao, "Variable rate reaching law for discrete time variable structure control systems," Asian Journal of Control, vol. 3, pp. 16-21, 1999.

[49] S. Sarpturk, Y. Istefanopulos, and O. Kaynak, "On the stability of discrete-time sliding mode control systems," IEEE Transactions on Automatic Control, vol. 32, no. 10, pp. 930-932, 1987.

[50] Y. Zhang, Q. Zhu, G. Ma, and Y. Guo, "An improved reaching law of SMC for spacecraft tracking system," in Proceedings of the IEEE International Conference on Information and Automation, pp. 907-911, Lijiang, China, August 2015.

[51] E. H. Mamdani and S. Assilian, "An experiment in linguistic synthesis with a fuzzy logic controller," International Journal of Human-Computer Studies, vol. 51, no. 1, pp. 1-13, 1975. 


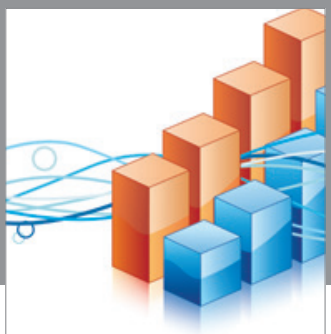

Advances in

Operations Research

vatem alat4

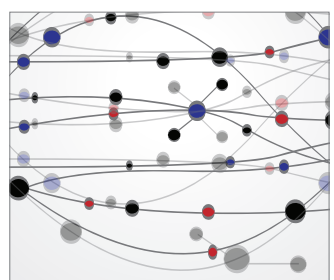

\section{The Scientific} World Journal
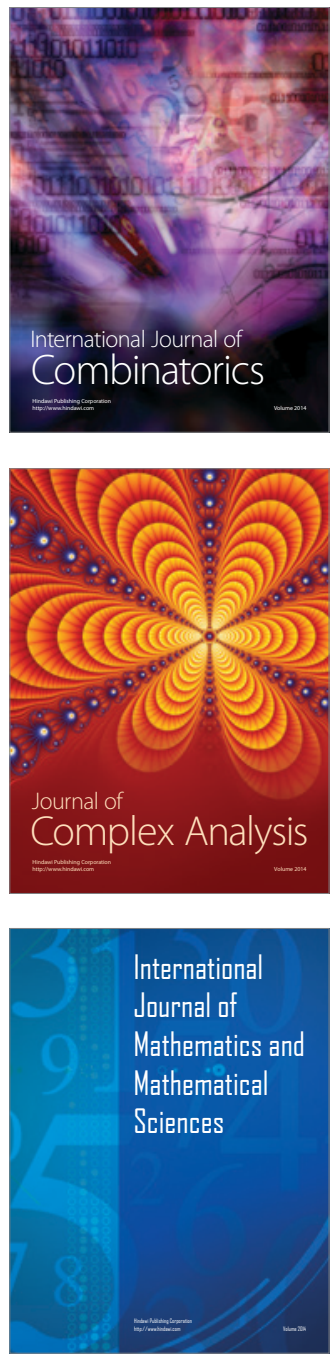
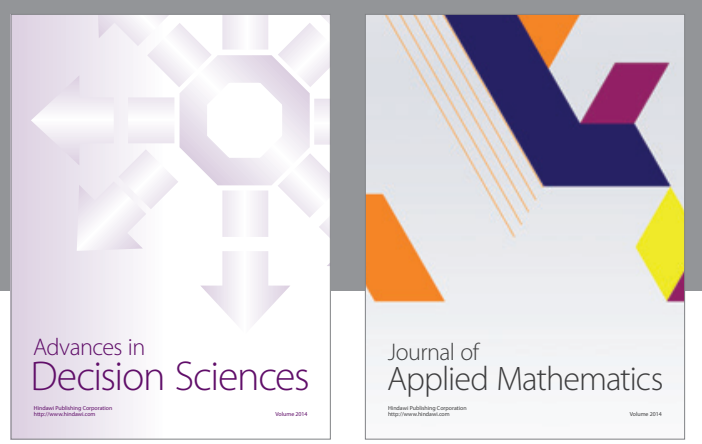

Algebra

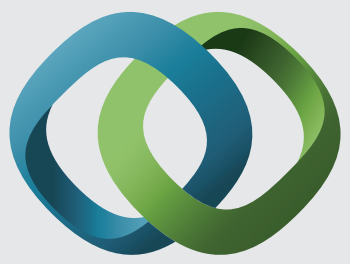

\section{Hindawi}

Submit your manuscripts at

http://www.hindawi.com
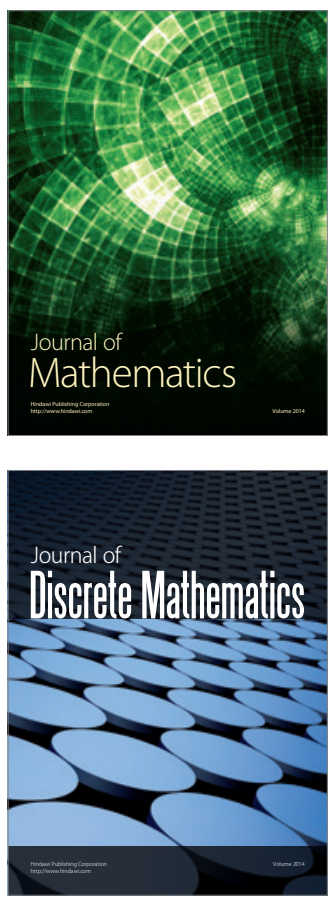

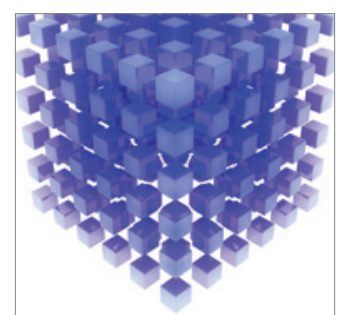

Mathematical Problems in Engineering
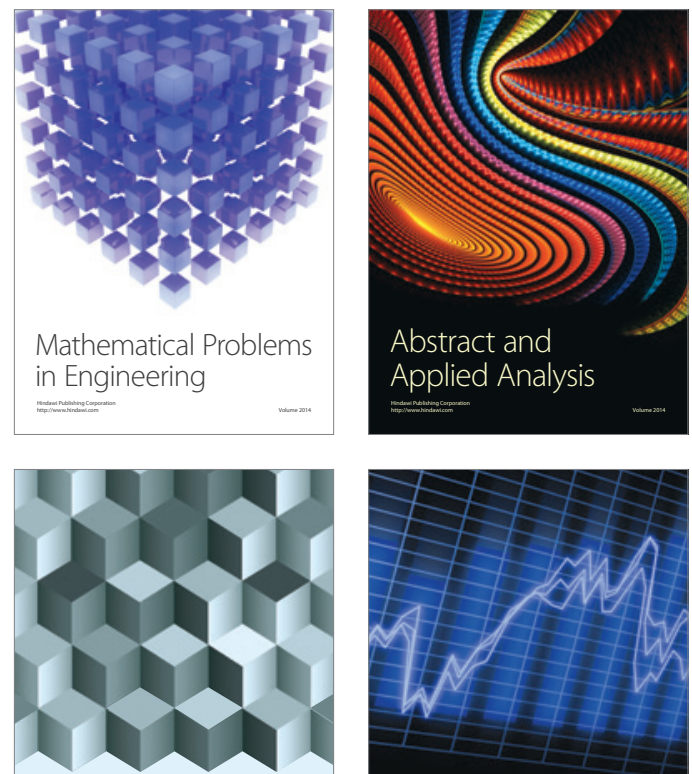

Journal of

Function Spaces

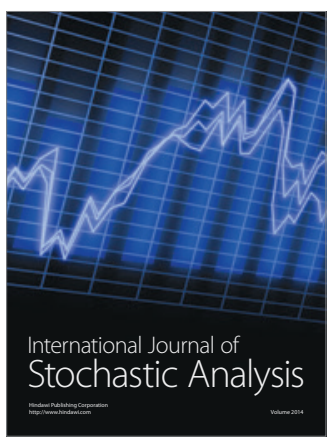

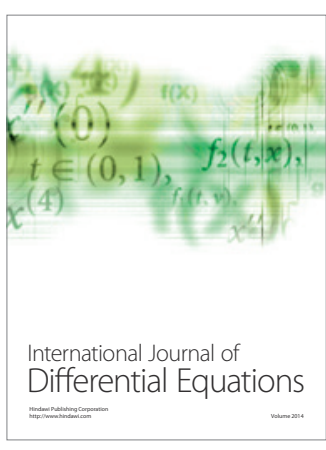
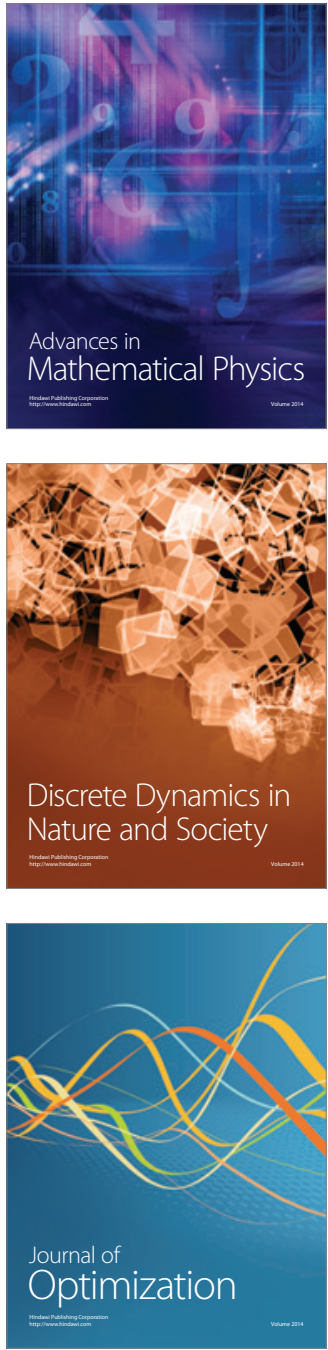